\title{
Reseña de Xeomorfoloxía e paisaxes xeográficas, catro décacas de investigación e ensino: homenaxe a Augusto Pérez Alberti
}

\author{
Review of Xeomorfoloxía e paisaxes xeográficas, catro décacas \\ de investigación e ensino: homenaxe a Augusto Pérez Alberti
}

Francesc Xavier Roig-Munar ${ }^{1}$

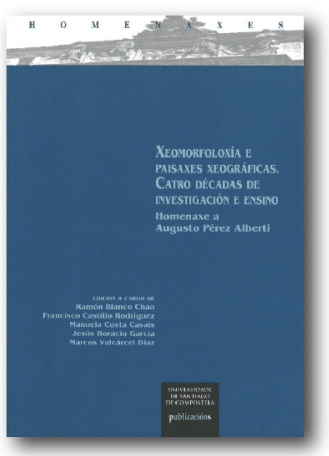

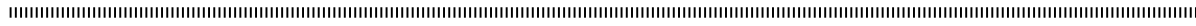

Editores: Blanco Chao, R., Castillo Rodríguez, F., Costa Cascais, M., Horacio García, J. y Valcárcel Díaz, M.

Título: Xeomorfoloxía e paisaxes xeográficas, catro décacas de investigación e ensino: homenaxe a Augusto Pérez Alberti

Año: 2018

Ciudad: Santiago de Compostela

Editorial: Universidade de Santiago de Compostela. Servizo de Publicacións e Intercabio Científico

Páginas: $570 \mathrm{pp}$

ISBN: 978-84-16954-96-4
Al final de la trayectoria académica son muchos que pasan desapercibidos, y son muchos los que dejan un escaso legado, tanto científico como divulgativo. No es el caso del Dr. Augusto Pérez Alberti, catedrático de Geografía de la Universidade de Santiago de Compostela, al que tuve la oportunidad de conocer en las I Jornadas de Geomorfología litoral celebradas en 2000 en Cádiz, organizadas por la Sociedad Española de Geomorfología y de la Sociedad Geológica de España, así como tenerlo de tribunal en mis tesis doctorales, y seguir en constante contacto con el. Augusto ha sido, y aun es, como le gusta decir, investigador activo. Es un científico reconocido, versátil, observador, crítico, meticuloso e impulsor del análisis crítico del paisaje gallego. Durante sus más de 40 años dedicados a la geomorfología, en todos sus aspectos, se ha convertido en un referente estatal en temas de geomorfología litoral, especialmente en costas rocosas. Fruto de su jubilación como profesor, y no como investigador, el Dr. Ramón Chao, profesor de la Univ. De Santiago, ha reunido a más de cincuenta colegas para crear el libro Xeomorfoloxía e paisaxes xeográficas, catro décacas de investigación e ensino homenaxe a Augusto Pérez Alberti, que recoge las principales disciplinas y líneas de investi- gación a través de las cuales, a lo largo de su larga i dilatada carrera, Augusto ha trabajado. Como son la geomorfología, con especial atención a la geomorfología costera, la geomorfología glaciar y periglacial, la hidrología, el estudio del paisaje, el paleoambiente y la planificación territorial, sin menospreciar su gran actividad como divulgador.

El libro incorpora las aportaciones de artículos, estudios, proyectos e iniciativas llevadas a cabo dentro de la línea y trayectoria investigadora tratada por Augusto, donde se recopilan 25 artículos relacionados. Estos han sido realizados por autores estatales y extranjeros, todos ellos expertos y con vinculación directa con el homenajeado, aunque seguramente, y debido a su dilatada trayectoria no están todos los que deberían estar. Las lenguas utilizadas en los trabajos son el gallego, el portugués, el castellano y el inglés.

En el libro podemos encontrar diferentes temáticas, todas ellas con un eje común, la geografía física y el paisaje, así como las aportaciones de Augusto a la geomorfología. Como grandes bloques en el libro podemos leer diferentes trabajos sobre medios litorales arenosos, como es el análisis de la progradación de un sistema playa-duna en la costa gallega, y un trabajo sobre depósitos litora- 
les cuaternarios en el litoral gallego. Podemos leer también un trabajo sobre modificaciones ambientales estuarias en la costa asturiana. Se presenta un trabajo sobre la interacción de costas arenosas con acantilados excavados en rocas blandas en el litoral gaditano. A nivel más genérico podemos leer una interesante reflexión sobre la importancia de las morfologías dunares en la estabilización costera, aportando varios ejemplos estatales. Destaca el trabajo realizado sobre el medio litoral de las islas Cíes, analizando la dinámica del nitrógeno y la aportación de este relacionado con los excrementos en los suelos ocupados por una colonia de gaviotas patiamarillas. La costa rocosa también queda representada en el trabajo de Alan Trenhaile, gran colaborador de Augusto, con un trabajo de evaluación crítica de del estado actual y dirección futura en los estudios de costa rocosa. Así mismo destacamos el trabajo sobre la costa rocosa de Cerdeña, analizando acantilados en la costa E de la isla.

Los trabajos de paisaje tienen su importante papel en el libro, como es el trabajo sobre la evolución del paisaje en la sierra de Ancares, o el interesante trabajo sobre el valor de los bocetos en el proceso de transformación paisajística, en el caso del Ebro a su paso por Zaragoza.

El libro acoge buenos ejemplos de trabajos sobre periglaciarismo, en referencia a la dilatada experiencia del homenajeado sobre este tema. Encontramos trabajos de retroceso glaciar en el Antártida, y una revisión y síntesis de las aportaciones del clima frío en diversos territorios del estado. Dentro del campo fluvial podemos leer ejemplos de trabajos sobre conos aluviales en Argentina o una detallada radiografía geomorfológica de dos ríos de Galicia. Dentro de esta misma línea podemos consultar el trabajo sobre cartografía subterránea en Porto (Purtugal), y un inédito trabajo sobre las paleoalteraciones en depósitos torrenciales en Galicia. Dentro del campo del periglaciarismo destaca el trabajo sobre la revisión y síntesis de las aportaciones sobre procesos de clima frío extremo NE peninsular de la cordillera Bética, donde los autores hacen referencia a las morfologías de Aitana, que llamaron la atención al autor homenajeado. Destacamos el trabajo sobre legado de la glaciación en la serra do Xistral, NW de Iberia, realizado por Valcarcel y Sampedro-Guimerey, donde se habla de los trabajos pioneros de Pérez-Alberti que permitieron mostrar la relevancia de las huellas glaciares en el relieve, y siguiendo su trayectoria iniciada en una etapa de su carrera académica centrada en el periglaciarismo.

Cabe destacar de los trabajos del libro aquellos que hacen referencia específica al estudio, apor- tación y/o reflexiones realizadas por Augusto, y donde los autores recogen tanto sus experiencias compartidas como su aportación académica. El trabajo O Norte de Portugal revisitado, publica, 20 años después, y actualizado, las reflexiones realizadas por la autora del trabajo con las aportaciones que realizó Augusto en la década de los 90 en un viaje a la denominada "Galizia do Sul". El trabajo Diálogos sobre el paisaje y reflexiones para la ordenación litoral recoge una entrevista realizada por Borobio y Castillo a Pérez-Alberti, con las reflexiones asociadas a las preguntas realizadas, ordenadas y de forma sistemática, donde la geografía física, la ordenación territorial y el paisaje son los grandes ejes, especialmente la relación de la geografía física aplicada a través de su obra científica y divulgativa. El trabajo-entrevista concluye en uno de los hechos olvidados actualmente en la planificación y gestión territorial; el alcance global de las acciones dentro del sistema debido a la complejidad que lo sustenta como territorio, con su base gravitacional en la geografía física y la importancia de su gestión. Los autores recogen como síntesis un decálogo de 10 principios sobre ordenación territorial, fruto de la entrevista, entre los que destaca la construcción y difusión del conocimiento, tan despreciado actualmente entre los investigadores debido a unos criterios de evaluación que penalizan su relación con la sociedad y promocionan la publicación de sus investigaciones en grandes revistas que no llegan a la población. La geografía física y la ordenación del territorio en la obra del profesor Pérez Alberti son tratados por Pérez-Chacón, donde se reflexiona sobre las aportaciones a la geografía física en la ordenación del territorio, considerando sus estudios territoriales en el ámbito territorial de Galicia, haciendo hincapié en el análisis de la pasión demostrada por del paisaje gallego, con una visión física como base del paisaje.

La publicación incorpora numerosas aportaciones bibliográficas, documentales y gráficas directas e indirectas de Pérez-Alberti, así como un relato de su dilatada aportación científica y divulgativa, en las que ha participado y ha tenido un papel destacado. El libro constituye en parte una obra del homenajeado para comprender el papel jugado en los temas tratados y especialmente el papel de la geografía física en la transformación territorial y paisajística, así como sus potencialidades para el futuro. Es de agradecer la labor de los coordinadores del libro, ya que han sabido recopilar 25 trabajos directamente relacionados con Pérez-Alberti, que contribuyen a recoger parte de los trabajos asociados a su amplia obra y tratados por los autores que han participado en el libro. 